\title{
Factors Determining the Strength of Organizational Culture from Togetherness, Intensity and Morale
}

\author{
Vladisik Palovac \\ University of Pardubice, Czech Republic
}

\begin{abstract}
This article discusses the factors that determine the strength of public organizational culture in terms of togetherness, intensity and morale. The method used is a mix of methods or a mixture of qualitative and quantitative. Togetherness increases if work is done together outside the room, but morale has the same inside and outside the room, but togetherness will be high if work activities are carried out outside. Organizational culture is a reflection of the formal and informal organizations formed within the organization concerned. Togetherness and group dynamics, namely encouraging their work not to be individualized and the center of power not in one hand. The main step that we really need to do is to select the best seeds or the best employees to be united into a team. However, keep in mind that good employees don't mean they don't have any shortcomings.
\end{abstract}

Keywords: Organization, Culture, Intensity

Received: September 12, 2020

Received in Revised: September 24, 2020

Accepted: September 27, 2020

\section{Introduction}

Culture is a way of life that is developed and shared by a group of people and is passed on from generation to generation. Culture is made up of many complex elements, including religious and political systems, customs, language, tools, clothing, buildings and works of art. Culture is a comprehensive lifestyle. culture is complex, abstract, and broad. Many aspects of culture also determine communicative behavior. These socio-cultural elements are scattered and include many human social activities. Thus, it is culture that provides a coherent framework for organizing one's activities and allows them to predict the behavior of others.

Schein (1991) and the opinion of Caudron (1994) stated that only companies that have quality human resources will be able to compete in global competition. To manage human resources that are quality, resilient, and well coordinated, good management techniques are also needed. In creating quality human resources in the context of strategic planning or corporate strategic policies, it turns out that the implementation of the human resource management practices above is deemed insufficient.

One of the internal strategic policies that can be taken by the management of the organization in optimizing the quality and achievement of employees is by empowering and disseminating the corporate culture.

Company culture is able to provide direction for the survival of the company and provide a unique identity for it. In order for this to really happen, it is necessary that the company culture be well socialized so that it can be internalized within its members. For this purpose, company leaders play a very important role, both in instilling the same understanding and perception of the culture in each of its members, and in providing an example by demonstrating the same attitudes and behaviors as the culture of the company. What is expected in the end is that every individual in the company can live the corporate culture which is their unique identity as a member of a group. The corporate culture is really formed when the company is distinguished from other companies, which can be seen from how the leaders and all members work and 
interact which will encourage them to achieve clear goals of the company. The more the corporate culture can adapt to various changes, for the sake of continuity and achievement of company goals, the culture is considered a good corporate culture, a strong culture in its true sense.

Organizational culture is a system of sharing the values and beliefs it attracts with people in a company, organizational structure and control systems to generate behavioral norms. Culture is the values that guide human resources to deal with external problems and efforts to integrate into the company, so that each member of the organization must understand the values that exist and how they should act or behave. Company culture or work culture, is indeed difficult to define explicitly and difficult to measure, but it can be felt by employees in the company. Therefore, an organization is formed from a collection of individuals with different characteristics, characteristics, skills, education and experience backgrounds in life, it is necessary to recognize views that are useful for achieving the mission and organization.

According to Newstrom \& Davis (2002) organizational culture is a reflection of the formal and informal organizations formed within the organization concerned, all of which form common norms, beliefs or perceptions that will be shared by all members of the organization. Another definition by Peterson (1999) states that organizational culture includes beliefs, ideologies, language, rituals, and myths. According to Narayana \& Nath (1993) organizational culture is corporate culture defined as a pattern of artifacts, beliefs, norms, values and reasons held by the organization (Schein, 2010).

Creemers and Reynolds (2000) state that organizational culture is a pattern of beliefs and expectations shared by organizational members. Meanwhile, Greenberg et al (1993) emphasized organizational culture as a cognitive framework that contains attitudes, values, behavioral norms, and expectations of organizational members. Work intensity and enthusiasm are required in various company activities.

\section{Methods}

This type of research is a mix of methods, namely the combination of qualitative and quantitative. Survey research is research that intends to explore existing data in the field to answer the problems that have been formulated. The population in this study were government agency employees. A total of 120 samples from 1000 population. The data obtained from the research results were analyzed using descriptive statistical analysis and inferential statistics. Descriptive statistical analysis was performed by describing the data from all variables in the form of frequency distributions and percentage values.

\section{Results and Discussion}

Organizational culture according to Willcoxson \& Millett, (2000) is a set of norms, beliefs, principles, and ways of behaving that together provide unique characteristics for each organization. Kast \& Rosenzweig (1974) define organizational culture as a system of shared values and beliefs that interact with the people of a company, organizational structure and control systems to produce norms of behavior. Gibson (2012) states that organizational culture is an organizational personality that affects the way individuals act in the organization. Another definition according to the description above is part of the concept of cultural strength which explains that a strong corporate culture will guide each individual and group in the same direction, create a comfortable work environment and provide freedom to innovate for employees, these things have a positive impact on company performance. generally. The factors that determine the strength of organizational culture are togetherness, intensity, morale. 


\section{Togetherness}

Togetherness and group dynamics, namely encouraging the way it works is not individual and the center of power is not in one hand. Something that is very difficult in a work relationship is building cooperation in group work. Even though humans know that it is impossible to solve matters individually, nevertheless when it comes to working together sometimes experiences difficulties. Togetherness is the extent to which members of the organization share core values. The degree of togetherness is influenced by the elements of orientation and reward. The orientation is intended to provide guidance to members of the organization, especially new members, either through the guidance of a senior member for new members or through training programs. While rewards can be in the form of salary increases, positions, promotions, gifts, and other actions that help strengthen the commitment to the core values of the organizational culture.

\section{Intensity}

Work intensity is defined as activities related to the capacity for that job. Intensity is the degree of commitment from organizational members to the core values of the organizational culture. The degree of intensity can be both an outcome and a reward structure. Employees' desire to carry out cultural values and work increases when they are rewarded. The factors that determine the strength of organizational culture are firstly the togetherness factor which consists of orientation or coaching and the reward factor in the form of salary, promotion, prize. The second factor is the intensity to which employees are committed to the core values of the organizational culture.

\section{Individual work spirit}

The main step that we really need to do is to choose the best seeds or the best employees to be integrated into one team. However, keep in mind that good employees don't mean they don't have any shortcomings. The purpose of this first point is not to separate those who are superior and those who are less.

However, if possible, would it be better if we chose the same team members in a group. Where in the past, they have worked together. The goal is that they give superior results again, because they already know each other's advantages and disadvantages of each member. Thus, this makes it easier for them to complement each other. Keep away from thinking that forming the same team members is like being picky. Of course not. Obviously this aims to build team morale like never before.

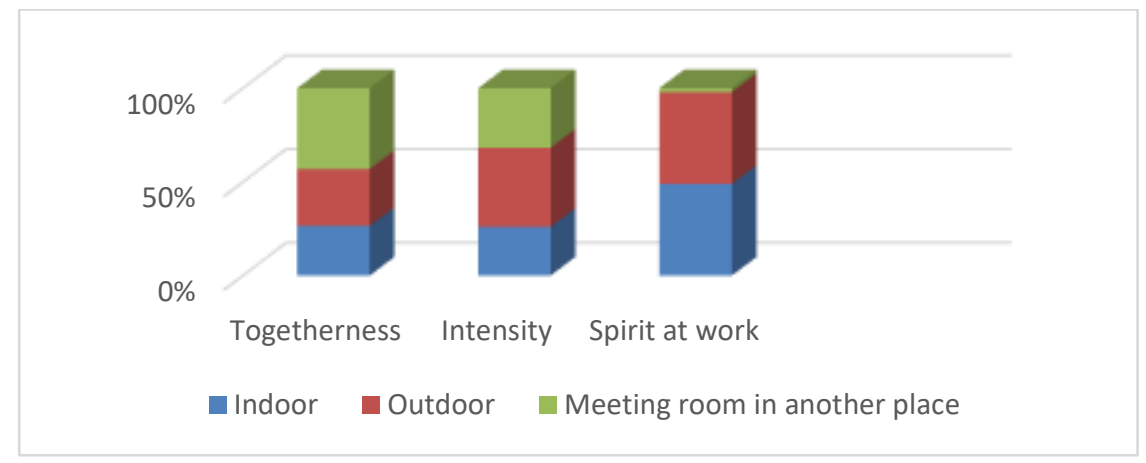

Figure 1. Diagram of various work situations

Togetherness increases if work is done together outside the room, but the morale of work has the same inside or outside the room, but togetherness will be high if work activities are carried out outside. 
A strong corporate culture will have a positive effect on business performance because it can provide extraordinary motivation for employees. With a strong corporate culture, it means that employees in the company have a belief in the same cultural values. This will create a comfortable work environment where employees feel valued, resulting in employee motivation to be loyal to the company which in turn encourages them to achieve the work performance that the company wants.

Beaumont (1993) argues that in organizations that view human resources as the main organizational competitive advantage, there is a positive correlation between strong organizational culture and organizational work performance. Implementation of a strong organizational culture, namely in the form of a culture that underlies the formation of leadership skills and individual managerial skills will increase motivation and individual employee commitment to work. To build teamwork spirit is to encourage all team members to respect each other. It doesn't matter who he is and what position that person has. Feeling respected and valued is a right that everyone needs to accept. By feeling respected by their colleagues, they will feel that their presence is really needed by others.

The process of socializing or alkalizing organizational culture. Organizational culture is taught to new members actually by discovering some cultural elements, but we only learn surface aspects. This happens because the basic assumptions as the core of culture will not be revealed in the rules of behavior taught to new members because basic assumptions are aspects that cannot be seen and are not visible on the surface. Leaders must be selective in accepting prospective employees. Employees must meet the specified qualifying requirements for them to be able. guided by the value system and norms contained in the organizational culture. Employee placement must be in accordance with their abilities and areas of expertise. Organizational culture can be in the form of discipline. For example, in terms of accuracy in completing the requested order, a friendly culture to customers, not coming to the office late and many more.

Deepening the field of work of employees and understanding the duties, rights and obligations of the leadership need to be done Employee work deepening can be done through education and job training in accordance with an analysis of their needs and problems. Organizational performance needs to be measured periodically every 6 months or at least every year so that its progress can be evaluated from year to year. Improving organizational performance must be balanced with the giving of fair and proper non-material and material awards to each individual organization who achieves. Cultivating loyalty to the main values of the organization, loyalty to the main values such as prioritizing providing the best service to consumers.

\section{Conclusion}

Togetherness increases if work is done together outside the room, but morale has the same inside and outside the room, but togetherness will be high if work activities are carried out outside. Organizational culture is a reflection of the formal and informal organizations formed within the organization concerned, all of which form common norms, beliefs or perceptions that will be embraced by all members of the organization. Organizational culture is a corporate culture defined as a pattern of artifacts, beliefs, norms, values and reasons held by the organization. The function of organizational culture, divides the five functions of organizational culture, plays a role in determining boundaries and delivering a feeling of identity for organizational members.

\section{References}

Beaumont, H. (1993). Martin Buber's "I-Thou” and Fragile Self Organization: Contributions to a Gestalt Couples Therapy'. British Gestalt Journal, 2(2), 85-95. 
Caudron, S. (1994). Motivating creative employees calls for new strategies. Personnel Journal, 73(5), 103-106.

Creemers, B., Scheerens, J., \& Reynolds, D. (2000). 10 Theory Development in School Effectiveness Research. The international handbook of school effectiveness research, 283.

Gibson, J. L. I., Ivancevich, J. M., \& Donelly Jr, J. H. (2012). Organization Behavior Structure Processes. Eight Edition. Boston: Richard D. Irwin Inc.

Greenberg, J., Baron, R. A., \& Grover, R. A. (1993). Behavior in organizations: Understanding and managing the human side of work.

Kast, F. E., \& Rosenzweig, J. E. (1974). Organization and management: A systems approach. McGraw-Hill.

Narayana, V. K., \& Nath, R. (1993). Organizational theory. Burr Ridge, IL: InA/in.

Newstrom, J. W., \& Davis, K. (2002). Organizational behavior (1 Ith ed.). New York: McGrawHill Higher Education.

Peterson, M. A. (1999). Organization, segregation and object recognition. Intellectica, 28(1), $37-51$.

Schein, E. H. (1991). What is culture. Newbury Park, CA: Sage Publicatios, 243-253.

Schein, E. H. (2010). Organizational culture and leadership (Vol. 2). John Wiley \& Sons.

Willcoxson, L., \& Millett, B. (2000). The management of organisational culture. Australian Journal of Management and Organisational Behaviour, 3(2), 91-99. 